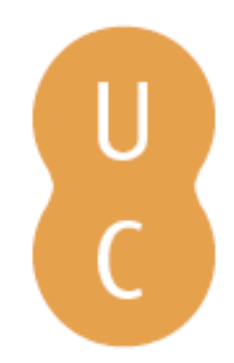

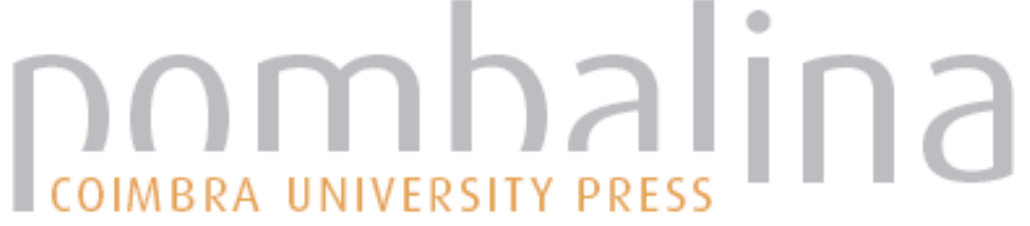

\section{Retrato e anti-retrato: o grande homem em Eça de Queirós}

\author{
Autor(es): Santana, Maria Helena \\ Publicado por: Imprensa da Universidade de Coimbra \\ URL \\ persistente: URI:http://hdl.handle.net/10316.2/32579 \\ DOI: $\quad$ DOI:http://dx.doi.org/10.14195/978-989-26-0442-8_11
}

Accessed : $\quad$ 26-Apr-2023 14:04:09

A navegação consulta e descarregamento dos títulos inseridos nas Bibliotecas Digitais UC Digitalis, UC Pombalina e UC Impactum, pressupõem a aceitação plena e sem reservas dos Termos e Condições de Uso destas Bibliotecas Digitais, disponíveis em https://digitalis.uc.pt/pt-pt/termos.

Conforme exposto nos referidos Termos e Condições de Uso, o descarregamento de títulos de acesso restrito requer uma licença válida de autorização devendo o utilizador aceder ao(s) documento(s) a partir de um endereço de IP da instituição detentora da supramencionada licença.

Ao utilizador é apenas permitido o descarregamento para uso pessoal, pelo que o emprego do(s) título(s) descarregado(s) para outro fim, designadamente comercial, carece de autorização do respetivo autor ou editor da obra.

Na medida em que todas as obras da UC Digitalis se encontram protegidas pelo Código do Direito de Autor e Direitos Conexos e demais legislação aplicável, toda a cópia, parcial ou total, deste documento, nos casos em que é legalmente admitida, deverá conter ou fazer-se acompanhar por este aviso.

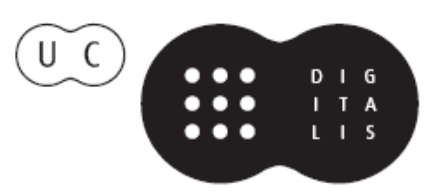


Aurelio Pérez Jiménez, Joșé Ribeiro Ferreira

e Maria do Céu Fialho

(COORdinadores)

\section{Adminiftri Principum.}

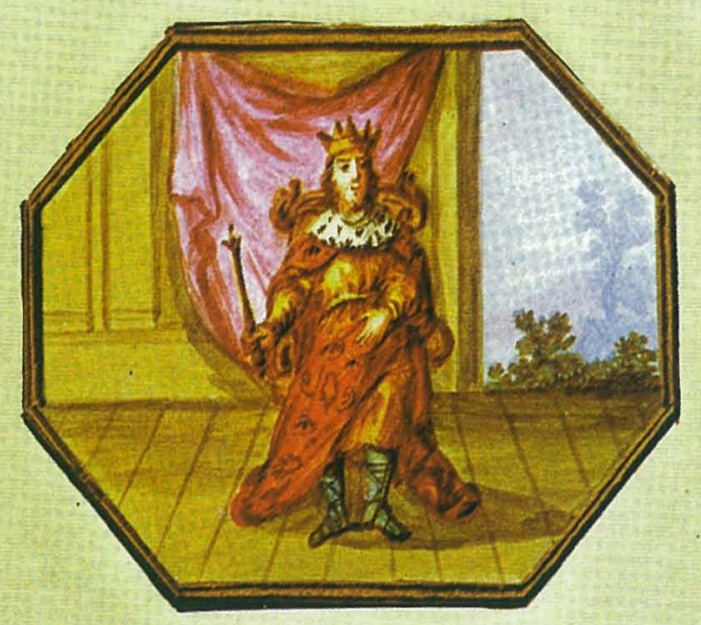

\section{EMBLEM A LIV.}

En tibi plura gerit, quàm lumina prabuit Argos Rex; Aures totidem, quin totidemó, manus. Hec opus Imperio, fidis fupplenda Minijtris, Regi bi funt aures: lumina clara, manus.

\section{- Retrato e a Biografia como estratégia de teorização política}

IMPRENSA DA UNIVERSIDADE DE COIMBRA

Universidad de MálaGa 
(Página deixada propositadamente em branco) 
Aurelio Pérez Jiménez

José RIBEIRo FERREIRA

Maria do Céu Fialho

O RETRATO LITERARIO E A BIOGRAFIA COMO ESTRATÉGIA

\section{DE}

TEORIZACCÃO POLITICA

IMPRENSA DA UNIVERSIDADE DE COIMBRA

UnIVERSIDAD DE MÁlaGa

2004 
Obra publicada com a colaboração de:

Centro de Estudos Clássicos e Humanísticos (Universidade de Coimbra)

International Plutarch Society

Primera edição, Junho de 2004

(c) IMPRENSA DA UnIVERSIDADE DE COIMBRA

(c) Área de Filología Griega. Universidad de Málaga

Coordenação editorial:

Imprensa da Universidade de Coimbra

Área de Filología Griega de la UMA

ISBN: 972-8704-25-9 (PORTUGAL)

ISBN: 84-608-0166-7 (ESPANHA)

Depósito Legal: MA-1420

Impresso em Espanha

Execução gráfica:

IMAGRAF IMPRESORES, S.A.

c/ Nabucco 14

29006 Málaga

Tfno. 952328597

Página de rosto:

"Dos Princepes Transùmptos verdadeiros": Francisco António Novaes Campos, Principe perfeito. Emblemas de D. Joâo de Solórzano. Edição fac-similada do manuscrito da Biblioteca Nacional do Rio de Janeiro oferecido ao Príncipe D. João em 1790 (Prefácio, introdução, comentário e índices por Maria Helena de Teves Costa Ureña Prieto), Instituto de Cultura e Língua Portuguesa, Lisboa, 1985, Emblema LIV, p. 114. 


\title{
RETRATO E ANTI-RETRATO: O GRANDE HOMEM EM EÇA DE QUEIRÓS
}

\author{
Maria Helena Santana \\ Universidade de Coimbra
}

Numa crónica de 1892, intitulada "Os Grandes Homens de França”, Eça de Queirós glosa, com a habitual ironia, este tema que atravessa de forma recorrente a sua obra a partir dos anos 80: o perfil do grande homem nos tempos modernos. Vem o texto a propósito da recente morte de Renan, e da discussão que despoletara em França a escolha dos heróis dignos de repousarem no Panteão Nacional, ao lado de Vítor Hugo, Voltaire e Rousseau. Para uma república moderna e positivista, apenas políticos, pensadores, artistas e cientistas reúnem algum consenso para o que então se chamava a canonização secular; mas a selecção torna-se muito complicada, dada a abundância dos talentos, a necessidade de satisfazer os vários grupos de pressão e, sobretudo, a ausência dum critério que englobasse ao mesmo tempo a ideologia das classes dirigentes e o sentimento popular. Depois de muitas considerações irónicas, em que ressaltam as aporias do debate, Eça tenta por seu turno definir tão polémico conceito:

O grande homem é aquele que pelo raciocínio atingiu uma maior soma de verdade, ou pela imaginação as maiores formas de beleza, ou pela acção os mais altos resultados, do que todos os seus contemporâneos na latitude do seu século. Esta obra superior em verdade, em beleza, em bondade ou utilidade, é produzida por um não sei quê que possui o grande homem, que se chama génio, cuja natureza não está suficientemente explicada, mas que constitui uma força infinitamente maior que o simples talento, o simples gosto ou a simples virtude ${ }^{1}$.

1 "Os Grandes Homens de França", in Notas Contemporâneas, Obras de Eça de Queiroz, Porto, Lello \& Irmão Editores, s.d., vol. II, p.1484.

A. Pérez Jiménez, J. Ribeiro Ferreira, Maria do Céu Fialho (edd), $O$ retrato literário e a biografia como estratégia de teorização política, Coimbra-Málaga, 2004, pp. 231-242. 
Dir-se-ia esta a fórmula incontestável, não fora o insanável problema do relativismo histórico e cultural que afecta a imagem da virtude, os conceitos de estética ou os sistemas de pensamento. Na falta de melhor solução, Eça conclui pelo critério da adesão popular - "o instinto das turbas" - que é de tipo mais religioso do que racional. Vítor Hugo ficaria assim como herói exclusivo da França moderna, por ser, no sentir da multidão, um nome vago, mas o único cuja grandeza dispensa demonstração.

Se deixarmos de lado o teor circunstancial da argumentação, e bem assim a declarada hugolatria do autor, fácil se torna extrair desta crónica os tópicos essenciais: verdade, beleza, utilidade, bondade - é da equação destes valores que se pode configurar qualquer forma de eternidade, única marca do ser superior. Dito de outro modo, saber, arte, acção e santidade constituem as quatro formas intemporais de heroísmo; importa indagar qual a sua hierarquia e qual a sua viabilidade nos tempos modernos. De um ou de outro modo, Eça perseguirá esta ideia em quase todas as obras da maturidade.

Atentemos em primeiro lugar, e indo ao encontro do tema deste colóquio, no grande homem de acção. Este papel, outrora associado à figura do rei-guerreiro e reencarnando mais tarde no caudilho, tendia, no final do século XIX, a representar-se na figura mais plebeia e mais terrena do político constitucional. Aquele homem que, se quiser dirigir a acção colectiva, tem primeiro que a legitimar, o que implica submeter-se aos códigos, às escolhas dos dirigentes ou ao escrutínio popular. Mais pragmaticamente, aquele que (como se diz noutra crónica), se vê obrigado a sentir "o amargo cuidado do pão a adquirir, da situação social social a manter, da concorrência a repelir, da íngreme escada a trepar"2. A esse vulnerável estatuto o tinham de facto circunscrito, na Europa civilizada, a Revolução e a emergência das democracias.

Ao longo dos anos Eça não deixará de reconfigurar esta imagem, fixando-a em sugestivas biografias - algumas, poucas, ficcionais, a maioria de personalidades reais da cena política europeia. Comum a quase todas é a escolha da evocação post mortem, habitualmente reservada ao panegírico.

Este tipo de textos - a narração da vida de uma figura ilustre cujos feitos se consideram modelares, ou pelo menos dignos de registo - apresenta desde logo a vantagem de estar codificado por uma longa tradição literária e oratória; bastaria lembrar os géneros canónicos da hagiografia e da crónica régia medievais, ou ainda as Vidas, à maneira de Plutarco. Mas presta-se também, em virtude dessa mesma co-

2

"A decadência do riso", ibid., p.1479. 
dificação, a ser desvirtuado e parodiado, sem com isso perder a referência prestigiosa aos seus modelos. Tal derivação prende-se com a própria evolução da biografia enquanto género. A partir do século XVIII, os biógrafos começam a privilegiar o 'homem íntimo', adoptando uma atitude menos encomiástica. $\mathrm{O}$ passo seguinte seria a biografia irónica, na senda da famosa Life of Johnson, por Boswell (1791), em que se viria a inspirar a correlativa versão ficcional da 'Vida e Obras' de uma personagem singular ou mesmo excêntrica. Trata-se de um género subtilmente paródico, que se tornaria muito produtivo no século XIX; entre nós, as "Memórias e Notas" que precedem A Correspondência de Fradique Mendes constituem um notável exemplo. Em geral a narração é atribuída a um suposto amigo ou secretário do biografado, já que se parte do princípio de que o homem apenas se revela plenamente no conjunto da vida pública e da vida privada; só que o confronto abre caminho a todas as ambiguidades.

$O$ Conde de Abranhos pertence a esta dupla família genológica, simultaneamente antiga e moderna. O modelo desejável seria o de Plutarco, como se lê no proémio, ou ainda o de prosadores nacionais de referência, como Herculano, Rebelo da Silva, Castilho... Mas por falta de dotes retóricos a opção recaiu nas memórias íntimas, como o subtítulo sugere - Apontamentos biográficos, e reminiscências intimas por Z. Zagalo, seu secretário particular. A duplicidade estender-se-á à concepção do texto. Oficialmente apresenta-se como uma biografia apologética - a vida de um grande homem político que toda a Lisboa conheceu e chorou. Na verdade pretende ser "a exposição das pequenezes, estupidezes, maroteirinhas, e pequices que se ocultam sob um homem que um país inteiro proclama grande" ${ }^{\text {. }}$

Por razões não totalmente conhecidas, este texto, escrito em 1879, nunca chegaria a ser publicado em vida do Autor. Sabemos apenas que, contra a vontade do editor Chardron, Eça não queria que o seu nome figurasse na capa, o que terá motivado o desinteresse na edição. Na verdade, dispomos apenas de um rascunho da novela, mais tarde revisto e retocado pelo filho do escritor. Mas é o suficiente para percebermos os traços gerais da sua concepção do político português padrão: aquele que chega ao poder pelas vias complementares do nepotismo, todo feito de adulação e pequena intriga, e do arrivismo social; aquele que sobe, passo a passo, a 'escala', como então se dizia, da carreira pública: o grau de bacharel por Coimbra, o jornalismo oportunista, a cadeira de deputado; chegando aí, uma boa gestão da

3 Carta de Eça ao editor E. Chardron, de 23.6.1878 [ou 79?]. Cf. Correspondência, Obras de E.Q., vol. IV, p.1213. 
imagem, dos discursos floreados e dos silêncios - especialmente dos silêncios; uma hábil manipulação dos compromissos e, sobre tudo isso, a total ausência de ideias, de coerência, de princípios. Será decerto desnecessário ilustrar os episódios caricaturais e patéticos que conduziram Alípio Abranhos, que não sabia Geografia e tinha horror à navegação, à apetecida pasta de Ministro da Marinha... ${ }^{4}$

Ficamos esclarecidos, em suma, sobre o que não deve ser um político, pela estratégia retórica da denegação. Cito apenas um exemplo, retirado dum monólogo de Abranhos, no momento em que receava não ser agraciado com a pasta ministerial:

Era decerto um intruso de génio, mas quem considera o génio quando se trata de recompensar a amizade? [...] havia sobretudo o famoso Torres, que já fora duas vezes ministro da Marinha com Navarro; aquela pasta parecia pertencer-lhe como um património: tinha por si a experiência ganha, o seu talento de orador, a sua posição literária como um dos nossos mais estimados dramaturgos! Era um colosso! ${ }^{5}$.

Mas o texto também nos desvenda, graças à duplicidade do panegírico, o segredo da construção biográfica dum grande homem: ele consiste, por um lado, em comparar ironicamente os pequenos sucessos de Abranhos aos dos grandes heróis da História passada e recente - Aquiles, César, Roldão, o Cid, Robespierre, Napoleão, etc. -; mas também, e sobretudo, na referência sistemática aos grandes vultos literários da Antiguidade: Homero, Ésquilo, Cícero, Juvenal, Tácito, Plutarco - ora como eternizadores dos grandes feitos, ora como modelos dos grandes discursos, das grandes sátiras, das grandes elegias. O contraste dá-nos a real dimensão dum país de segundas figuras, cuja opinião pública, na verdade inexistente, se limita a ratificar os chavões parlamentares; em que tudo se resume ao triunfo da eloquência oca, o terrível vício nacional.

Deste retrato retiraria Eça as linhas-mestras da arte de caricaturar políticos, apurada mais tarde na contra-biografia de Pacheco, inserida na Correspondência de

4 A crítica à prática dos regimes constitucionais que transformaram o político num factotum, possuidor de competências em domínios totalmente opostos à sua formação, será retomada em outros textos de Eça. Numa das suas crónicas de Paris, o autor elogia um ministro que teve a resolução heróica de recusar um ministério por não se sentir competente. Eça considera-o "um homem de Plutarco", pela raridade moral do gesto (Ecos de Paris, Obras de E.Q., vol. II, p. 1179).

O Conde de Abranhos, ed. cit., vol. III, p. 397. Por comodidade de leitura, citamos sempre por esta edição, fazendo no entanto notar que não é a mais fiel ao texto do autor. Passaremos a indicar apenas o volume e a página. 
Fradique Mendes. A reductio, no sentido retórico e literal do termo, atinge aí a sua extrema expressão ao delinear o percurso duma possível glória nacional cujo “imenso talento" se construiu, por etapas sucessivas, em proferir um discurso, repetir uma frase, fazer um gesto. Da primitiva novela vem também o velho tópico de que só conhece verdadeiramente um homem quem o viu na intimidade - "em chinelos e 'robe de chambre" -; em última análise, a sua mulher e o seu criado. Tudo o mais releva da consagração da imagem pública, ou seja, da mitificação.

Passando agora aos políticos verdadeiros, necessário se torna encontrá-los fora do estreito espaço português. São notáveis, embora menos conhecidos, os retratos que Eça nos deixou, nas suas crónicas, de figuras históricas coevas. Interessantes, ainda, porque através deles se delineia a reflexão do autor sobre as condições de exercício do poder no contexto da Europa moderna. De acordo com a dualidade dos regimes em vigor na época, poderemos também subdividi-los em dois grupos: os chefes de Estado constitucionais e os imperadores autocráticos.

Casimir Périer, Sidi Carnot (ambos presidentes franceses), o Conde de Paris, Philippe d'Orléans (candidato ao trono, no exilílio) e de Lord Beaconsfield (o célebre Disraeli) pertencem, naturalmente, ao primeiro grupo. Todos eles são objecto de obituários de fina composição literária, em que se articula a caracterização da personalidade humana, o carácter que imprimiu (ou não imprimiu) ao cargo, a influência que recebeu da sua classe, da sua cultura, do meio que condicionou a sua acção. Deixaremos de lado a biografia de Lord Beaconsfield, por sinal a mais interessante, porque se trata de um caso singular de carisma romântico, dificilmente concebível como paradigma.

Dois traços comuns marcam o perfil dos restantes, para além de serem franceses: as excelentes qualidades humanas e cívicas, por um lado, e a quase total incapacidade de governar, no sentido forte do termo. Daí extrai o autor o paradoxo que resulta de as virtudes se tornarem defeitos quando não dispõem de terreno favorável à sua plena expansão. A ideia é explorada de forma distinta nos três textos. Quer o Conde de Paris, quer Casimir Périer, que, pelo perfil aristocrático, recebem visível adesão por parte do autor, reúnem todas as qualidades que lhes permitiriam, noutras circunstâncias, tornarem-se grandes governantes: saber, cultura, probidade, elevação moral, até mesmo bondade. No caso de Filipe d'Orleães ainda acresce a mais-valia da imagem e da raça, que faltam ao segundo. Ambos patriotas, de resto, desinteressados e respeitadores das leis democráticas. Por que falharam, então, o presidente e o candidato ao trono de França? Não perceberam, cada um a seu modo, os mecanismos da popularidade e as regras viciadas do jogo político tal como os criaram os regimes constitucionais. 
O conde de Paris era excessivamente modesto e tinha fama de forreta; mais: incorreu no erro de querer ser rei por plebiscito popular; não percebeu (e aqui se insinua o argumento subjectivo do autor) que as classes médias são extremamente ciosas dos seus valores, mas exigem aos monarcas o que ideologicamente repudiam: audácia, soberano desprezo pelas leis, fausto, prodigalidade. Não basta que seja culto, bom cidadão, que domine a sociologia e a economia política. Todo texto assenta, aliás, numa sintaxe condicional particularmente feliz: "se fosse... seria...". Daí que um verdadeiro príncipe, na acepção positiva do termo, esteja à partida, como se pode concluir, impedido de ser um rei. Périer ilustra, mutatis mutandis, um paradoxo do mesmo tipo: além da má imagem física, tinha, segundo Eça, o defeito de ser rico e de manter relações demasiado mundanas com a aristocracia. A República democrática não lhe perdoou a traição de classe; não lhe perdoou também a tibieza, quando ao mesmo tempo boicotava todos os seus gestos de decisão. Tal como o herdeiro do trono, teria sido um óptimo governante, se... Cedo verificou que desempenhava um cargo praticamente destituído de poder:

Como o nosso D. João VI, depois da revolução de 1820, ele só sabia de manhã, pelos jornais, o que se decretara, em seu nome, na véspera. Não era propriamente um chefe de Estado - era uma estaca de Estado. Estava ali plantado no Eliseu. [...]

Nestas condições, uma bela manhã [... ] sacudiu os ombros livres. Farto de ser uma estaca - quis tornar a ser um homem. O desejo é legítimo - e no 'gesto', como agora se diz, não deixa de haver audácia e elegância ${ }^{6}$.

Sidi Carnot encarna, em versão desqualificada, a mesma figura da inutilidade: "não era mais que a imagem ornamental e simbólica da República, como essa estátua de ouro da Vitória que protegia o Império Romano"7. Não tinha ideias, nem adversários. De resto, um bom burguês, bom cidadão, bom executante de política externa, un brave homme. Dada a impossibilidade de fazer o retrato biográfico dum homem que obviamente considera irrelevante, Eça opta neste caso por outra estratégia literária: sublinhar, pela ironia, a inverosimilhança da morte de Carnot: "o mais inocente, o mais legal, o mais irresponsável, o mais impessoal dos chefes de Estado, morrendo de uma punhalada, como César, como Henrique IV ou como Marat!”8. O

6 II, p. 1293-4. Salvo indicação em contrário, todos os retratos mencionados pertencem à obra cronística dos anos 80 e 90, reunida em Ecos de Paris, Cartas Familiares e Bilhetes de Paris.

7 II, p. 1223.

8

II, p. 1222. 
relato dos funerais, no texto seguinte, retoma o mesmo confronto antitético. Com a morte de Henrique IV, a França tremeu, o povo chorou, e no horizonte anuncia-se a Guerra dos Trinta Anos; com Carnot morto, nada de grave acontece; César morreu sem espalhafato mas com dignidade; Carnot agoniza num landau em corrida, na maior das confusões. Todo este espectáculo patético, comenta o autor, vem provar que "o chefe é apenas o remate decorativo do Estado", pelo que também o regicídio se transformou em "tragédia doméstica".

A nostalgia dos velhos tempos, em que o conceito ético e estético da autoridade não se tinha ainda desvalorizado em nome do seu moderno avatar - a legalidade -, parece de facto dominar a reflexão de Eça acerca dos sistemas políticos coevos. Não é bem assim. Os retratos de Guilherme II e de Alexandre III - um imperador autocrático e um czar todo-poderoso - mostram-nos que todo o sistema de exercício do poder no século XIX tem a sua face reversa. A posição ideológica do autor afirma-se aqui de forma muito mais consequente.

Guilherme II vem qualificado como 'um diletante da acção', ou seja, aquele que "compreende e sente com superior intensidade os prazeres infinitos que ela oferece"; como tal só é possível num chefe que se julga inspirado por Deus, com um império submisso, servido por um poderoso exército, ele constitui, à partida, um caso interessante. Ou constituiria, não fosse a circunstância de esse império ficar no coração da Europa civilizada, onde já ninguém acredita no poder divino, e de existir o risco sério de o voluntarista "apetecer a guerra". Eis, em resumo, o argumento político do texto. O perigo que representam os regimes despóticos advém da própria construção mitificada do déspota: está condenado a ser invencível, sob pena de a máscara trair o histrião. Mas a reflexão política não fica por aqui: Eça não deixa de lembrar que a lição da História augura um mau futuro aos povos que se julgam eleitos de Deus; e, não sem antes notar a responsabilidade dos filósofos alemães no compromisso com o status quo, deixa a esperança de que a cultura triunfe sobre a tirania:

Onde estão esses louvores ao direito divino dos Hohenzollerns, cantados por Strauss, por Mommsen, por Von Sybel? Tudo passou. A metafísica rosna descontente. Das duas pedras-angulares da monarquia prussiana, o filósofo e o soldado,

II, p. 1227 ss. A singular semelhança entre o relato deste atentado e o que, quase um século depois, viria a vitimar J.F. Kennedy leva-nos a constatar o relativismo da tragicidade: num outro contexto, os media promovem de novo.o reinvestimento trágico do 'regicídio', assumindo os contornos da mitificação colectiva. 
Guilherme II hoje só tem o soldado: - e o trono, sobrecarregado com o imperador e o seu Deus, pende todo para um lado, que é talvez o do abismo... ${ }^{10}$

O retrato de Alexandre III é mais elaborado, e também mais cruel. Homem e regime caracterizam-se mutuamente em função do seu anacronismo: ambos feudais e bárbaros, sem igual na História senão em tempos muito primitivos ${ }^{11}$. O chamado 'russianismo' do czar resume-se, caricaturalmente, ao seu lado mujique, do qual recebe a feição rude e pueril: "Do mujique tinha a robustez enorme e malfeita, o andar bovino e lento, o olhar cismador. Os seus prazeres eram os trabalhos rudes de homem dos campos, em luta com a Natureza áspera - desbastar mato, derrubar árvores, rachar lenha" "12. Daí decorre também o zelo doméstico da administração do reino: de dia, o 'grande mujique coroado' era um centralizador esfalfado; à noite, um terno pai de família, que servia o chá.

Da análise do seu reinado sobressai o famoso projecto de 'russificação' da Nação, ou seja, um exercício de imperialismo étnico que acabaria por isolá-la das restantes culturas europeias. Toda a História russa é passada em revista em contraste com a francesa, de forma a salientar o hiato civilizacional entre os dois povos e os dois regimes. No final, a situação da Rússia moderna representa-se pela imagem duma grande casa asiática, com' uma varanda sobre a Europa, mas mantendo no interior "um Oriente antigo e muito estranho, que nós não podemos compreender". Se a um país asiático só pode corresponder um governo autocrático, podemos inferir a moral da história: cada povo merece o seu chefe.

Nenhuma das figuras evocadas reúne condições para ficar na História. Não há, no espectro político europeu, um político que se possa de facto considerar um grande homem, ou porque os tempos são de anonimato colectivo - tempos de "muita turba e poucos homens" - ou porque, a existirem, os regimes os tornam

II, p. 1135.

11 Atente-se no confronto com o cesarismo romano: "Os césares não eram propriamente déspotas, tal como se entendia então o despotismo, e como ele existia no Oriente, sobretudo na Pérsia, onde não havia estado, nem leis, nem opinião, nem propriamente homens conscientes [...]. Decerto Roma viu formas violentas de tirania, sob certos príncipes de natureza perversa ou transviados por esse desequilíbrio da vontade absoluta que se chamou a "loucura cesariana". Mas eram crises transitórias - não situações normais. O cesarismo foi sempre na realidade uma monarquia temperada. [...] Em face dos Césares restavam ainda muitas forças vivas para os constranger e moderar. [...] O imperador da 12 Rússia é que não tem explicações a dar a ninguém, senão a Deus.” (p. 1272-4). II, p. 1275. 
intoleráveis. Acresce que não se torna grande quem apenas pode, ou quer: o meio, a 'raça', o momento (como diria Taine) criam condições favoráveis à sua emergência $^{13}$. Em última análise, o nome surge por "criação subjectiva da própria vontade, como o enredo de um romance", como se diz, a propósito de Lord Beaconsfield, que impôs a sua figura de forma absolutamente original. Possuía Disraeli o tal quid que faz o génio e que emerge da personalidade carismática ${ }^{14}$. Mas isso era possível num contexto romântico, irrepetível.

Resta portanto ao homem comum procurar as outras formas alternativas de heroísmo, ou seja, de eternização: o saber, a santidade e a Arte.

Sobre a eternidade do Saber - por natureza perecível - deixou-nos o autor d'A Cidade e as Serras um significativo testemunho naquele que seria o seu derradeiro romance. Aí se questiona, mais do que a utilidade, a importância relativa do conhecimento no cômputo geral da experiência humana. Aliás, em vários outros textos ensaísticos reitera-se a ideia de que o furor enciclopedista e racionalista do século XIX é o principal responsável pela morte de Deus e pelo desencantamento do mundo moderno.

O carisma da santidade, no sentido tradicional, está fora de questão, excepto do ponto de vista estético; mas se a santidade for entendida como apologia da perfeição individual, então sim, está ao alcance do homem comum; isso mesmo se diz no obituário do cardeal Manning, "Um santo moderno", ou ainda, numa versão diferente, no texto de homenagem a Antero, "Um génio que era um santo".

O problema é mais complexo no que concerne à Arte. Como tentei demonstrar noutro lugar ${ }^{15}$, Eça acreditava que a Arte podia constituir, pelo menos em termos relativos (comparada com a acção política, designadamente), uma forma maior de transcendência:

AArte é tudo - tudo o resto é nada. Só um livro é capaz de fazer a eternidade dum povo. Leónidas ou Péricles não bastariam para que a velha Grécia ainda vivesse, nova e radiosa, nos nossos espíritos: foi-lhe preciso ter Aristófanes e Ésquilo. [...] Nada há mais ruidoso, e que mais vivamente se saracoteie com um brilho de lantejoulas - do que a Política. [...]. Mas concebes tu a possibilidade de que daqui a cinquenta anos, quando se estiverem a erguer estátuas a Zola,

13 Veja-se o seguinte apontamento: “A Espanha é hoje, na Europa, a última nação heróica: - pelo menos é a última onde os homens, publicamente, e nas coisas públicas, se comportam com aquela arrogância, e bravura estridente, e magnífica imprudência, e soberba indiferença pela vida, e desdém idealista de todos os interesses, e prontidão no sacrificio, que constituem, ou nos parecem constituir, o tipo heróico [...]” (II, p.1173). 
alguém se lembre dos Ferry, dos Clemenceau, dos Cánovas, dos Bright? Podesme tu dizer quem eram os ministros do Império em 1856, há apenas trinta anos, quando Gustavo Flaubert escrevia Madame Bovary? ${ }^{16}$

Mas Eça também reconhece, nas entrelinhas desse mesmo texto, que os ventos da modernidade não vão de feição para qualquer heroísmo ou sacerdócio do homem de letras, tal como os definiram Carlyle ou Comte; sujeito às contingências do mercado e do consumo massificado, o escritor vê o seu verbo profético reduzido ao simples estatuto de "fazedor de livros", ou profissional das letras, como hoje se diria.

O tema deu lugar a uma oportuna resposta de Oliveira Martins, que, lendo no texto apenas o elogio contrastivo das respectivas actividades, procura resgatar a nobre missão do Político da fraca conceituação que o amigo lhe outorgava. Martins argumenta que também a política, ao lado do saber, da coragem e da caridade, pode ser e é "susceptível de tanta grandeza como as maiores manifestações do génio do homem". E lembra-lhe que enquanto os literatos pisam egoisticamente "um caminho de flores", no mundo real condena-se a uma "vereda espinhosa" todo aquele que se dedica a "fazer actos, res, non verba" $a^{\text {"17. }}$

Eça tinha consciência da verdade destas afirmações. O contrário implicaria desmentir todo um percurso geracional marcado pelo imperativo ético da ação e pela própria figura tutelar do autor de Nun'Álvares. Simplesmente, a questão colocava-selhe numa outra perspectiva, no final dos anos 80: a da possibilidade de exercer, em termos práticos e em termos estéticos, essa forma tradicional de heroísmo. Não por acaso, é ao mesmo historiador que poucos anos depois dirige, sobre o mesmo tema, uma das mais sugestivas cartas de Fradique Mendes. Vem a carta a propósito da recente fotografia de Ramsés II, mumificado. $\mathrm{O}$ fragmento que a seguir se transcreve servirnos-á de conclusão, porque nele se sintetiza a necrologia do grande homem:

Aí o tem V. agora diante de si, em fotografia, com as pálpebras baixas e sorrindo. E que me diz a essa face real? Que humilhantes reflexões não

Cartas de Inglaterra, II, p. 545.

15 "O heroísmo na era do desencantamento" - comunicação apresentada no Colóquio Outras faces de Eça de Queirós (Um mês com Eça centenário), Faculdade de Letras do Porto, 7-4-2000.

Pref. de Azulejos, do Conde de Arnoso, Notas Contemp., II, pp. 1441-2.

17 Oliveira Martins, "Pró Política" (A Província, 14-12-1886), in O. Martins, Dispersos, vol. II, Lisboa, Oficinas Gráficas da Biblioteca Nacional, 1924, pp. 106-12. Também Guerra Junqueiro, Camilo Castelo Branco e Mariano Pina reagiram a este texto. 
provoca ela sobre a irremediável degeneração do homem! [...] Eis aí verdadeiramente um Dono de homens! Compare esse semblante augusto com o perfil sorno, oblíquo e bigodoso dum Napoleão III; com o focinho de buldogue acorrentado dum Bismarck; ou com o carão do czar russo, um carão parado e afável que podia ser o do seu Copeiro-mor. Que chateza, que fealdade tacanha destes rostos de poderosos!

Donde provém isto? De que a alma modela a face, como o sopro do antigo oleiro modelava o vaso fino; - e hoje, nas nossas civilizações, não há lugar para que uma alma se afirme e se produza na absoluta expansão da sua força. [...]

Em conclusão: - a múmia de Ramsés II (única face autêntica do homem antigo que conhecemos) prova que, tendo-se tornado impossível uma vida humana, vivida na sua máxima liberdade e na sua máxima força, sem outros limites que os do prório querer - resultou perder-se para sempre, no tipo físico do homem, a suma e perfeita expressão da grandeza ${ }^{18}$. 


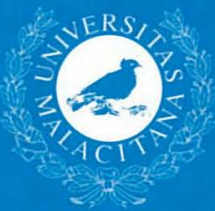

